\title{
ANATOMIA COMPARADA DAS FOLHAS DE ESPÉCIES DE PEPEROMIA (PIPERACEAE) - I. ONTOGÊNESE DO TECIDO AQÜÍFERO E DOS ESTÔMATOS ${ }^{1}$
}

\author{
Nathieli Keila Takemori ${ }^{2}$ \\ Cleusa Bona ${ }^{2}$ \\ Yedo Alquini ${ }^{2}$
}

Recebido em 30/06/2002. Aceito em 26/12/2002

\begin{abstract}
RESUMO - (Anatomia comparada das folhas de espécies de Peperomia (Piperaceae) - I. Ontogênese do tecido aquífero e dos estômatos). A maioria das espécies de Peperomia apresenta tecido que reserva água na face adaxial de suas folhas. Esse tecido pode variar em espessura, determinando maior ou menor suculência à folha. A fim de se determinar a origem de estruturas anatômicas relevantes ao grupo, o presente trabalho descreveu o desenvolvimento do tecido especializado na reserva de água, bem como a ontogênese dos estômatos de $P$. catharinae Miquel, P. emarginella (Sw.) C.DC., P. quadrifolia (L.) Kunth e P. rotundifolia (L.) Kunth. Para tanto, foram observadas folhas jovens do ápice caulinar e do primeiro nó subseqüente, em secções transversais e paradérmicas. As técnicas utilizadas foram as usuais para microscopia fotônica. Todas as espécies apresentaram tecido especializado na reserva de água, originado de divisões periclinais das células protodérmicas. A ontogênese estomática é mesoperígena, dando origem a estômatos anisocíticos, tetracíticos e estaurocíticos.
\end{abstract}

Palavras-Chave - Peperomia, epiderme múltipla, ontogênese estomática

\begin{abstract}
Comparative leaf anatomy of Peperomia (Piperaceae) - I. Ontogenesis of the aquiferous tissue and the stomata). Most species of Peperomia presents a water reservoir tissue on the adaxial surface of the leaf. This tissue can vary in thickness determining more or less succulence to the leaf. On purpose of determining the origin of important anatomic structures for this group, the present work describes the development of the water reservoir specialized tissue, as well as the stomata ontogenesis for $P$. catharinae Miquel, P. emarginella (Sw.) C.DC., P. quadrifolia (L.) Kunth and P. rotundifolia (L.) Kunth. Young leaves from the stem apex and the first node were observed in cross and paradermic sections. The techniques were the usual for light microscopy. All the species presented the water reservoir specialized tissue originated from periclinal divisions of protodermal cells. The stomata ontogenesis is mesoperigenous and it gives rise to anisocytic, tetracytic and staurocytic stomata.
\end{abstract}

Key words - Peperomia, multiple epidermis, stomata ontogenesis

\footnotetext{
Parte de Dissertação de Mestrado da primeira Autora

2 Departamento de Botânica, Setor de Ciências Biológicas (SCB), Universidade Federal do Paraná, C. Postal 19031, CEP 81531-990, Curitiba, PR, Brasil
} 


\section{Introdução}

A maioria das espécies de Peperomia Ruiz \& Pavon apresenta folhas providas de tecido especializado em reserva de água. Algumas delas apresentam elevado grau de suculência, o que muda consideravelmente a morfologia foliar (Kaul 1977). Esse tecido também funciona como filtro de luz (Krulik 1980; Sipes \& Ting 1985), transmitindo para o mesofilo apenas $70 \%$ da luz que incide na folha (Nishio \& Ting 1993). A alta capacidade de armazenar água compensa os períodos de seca que são muito comuns para espécies de hábito epifítico (Larcher 1995; Lambers et al. 1998; Helbsing et al. 2000). Apesar de muitos trabalhos chamarem esse tecido de hipoderme, a hipótese do tecido ser de origem epidérmica já havia sido levantada por Pfitzer (apud Solereder 1908).

As espécies da família Piperaceae sempre foram de interesse ornamental por sua folhagem vistosa (Mustard 1986; Judd et al. 1999). Além de interesse ornamental, as espécies desse gênero também despertam curiosidade por apresentarem características tanto de Magnoliopsida quanto de Liliopsida (Sprague apud Murty 1960), como os estômatos do tipo tetracítico (Pant \& Banerji 1965; Judd et al. 1999) e caule com sistema vascular de organização monostélica (Takemori 2002).

A fim de se determinar a origem de estruturas anatômicas relevantes ao grupo, o presente trabalho objetivou a descrição do desenvolvimento do tecido especializado em reserva de água, bem como a ontogênese dos estômatos de $P$. catharinae Miquel, $P$. emarginella (Sw.) C.DC., P. quadrifolia (L.) Kunth e P. rotundifolia (L.) Kunth.

\section{Material e métodos}

Peperomia catharinae foi coletada no Capão da Educação Física do Centro Politécnico, UFPR, Bairro Jardim das Américas e no Bosque Municipal Reinhard Maack, Bairro Hauer, ambos no Município de Curitiba, Paraná,
Brasil. P. quadrifolia e P. emarginella foram coletadas na Curva da Ferradura, Estrada da Graciosa, Paraná, Brasil. P. rotundifolia foi coletada no Município de Fênix, Paraná, Brasil. Parte do material foi herborizado e depositado no Herbário UPCB, registrado sob os números 45018-45025.

A fixação das amostras foi realizada com FAA 50 (formaldeído - ácido acético glacial álcool etílico 50\%, Johansen 1940) e conservadas em álcool etílico 70\%. A ontogênese dos estômatos foi observada em folhas jovens, do ápice caulinar e do primeiro nó subseqüente. As amostras foram analisadas em lâminas semipermanentes, as quais foram preparadas com folhas inteiras clarificadas e montadas em glicerina a $50 \%$. A ontogênese do tecido aquífero foi analisada através de secções longitudinais e transversais de folhas do ápice caulinar. As amostras foram desidratadas em série alcoólico-etílica e emblocadas em glicol metacrilato (GMA), de acordo com Feder \& O'Brien (1968), seguida das recomendações do fabricante. As secções transversais de $5 \mu \mathrm{m}$ de espessura foram obtidas em micrótomo rotativo e posteriormente coradas com azul de toluidina 0,05\% (O'Brien et al. 1965). As lâminas permanentes foram montadas com resina sintética (Entelan $\left.{ }^{\circledR}\right)$.

As ilustrações foram realizadas por intermédio de fotomicrografias feitas em fotomicroscópio e desenhos realizados em microscópio acoplado a câmara clara. As escalas foram projetadas sob as mesmas condições ópticas.

\section{Resultados e discussão}

Ontogênese do tecido aquífero - $\mathrm{O}$ tecido aquífero das folhas das espécies de Peperomia desenvolve-se a partir de divisões periclinais das células protodérmicas da face adaxial da folha, sendo, portanto, uma epiderme múltipla (Fig. 1-5 e 7-9). Após a primeira divisão periclinal da protoderme, as células externas se diferenciam e raramente sofrem novas divisões 
periclinais, enquanto as derivadas internas aumentam de volume e sofrem sucessivas divisões periclinais (Fig. 6 e 7). As células mais internas se especializam, passando a apresentar citoplasma escasso e vacúolo predominante. Enquanto isso, as células do segundo estrato continuam sofrendo divisões periclinais (Fig. 6). Durante o crescimento das células internas, a camada externa pode dividir-se anticlinalmente para acompanhar o aumento de superfície da folha. Em P. catharinae e $P$. quadrifolia, as células que reservam água apresentam constância de volume, sendo praticamente todas do mesmo tamanho na folha adulta (Fig. 8). Por sua vez, $P$. emarginella e $P$. rotundifolia apresentam o estrato mais interno da epiderme múltipla, ou seja, o estrato que faz conexão com o parênquima clorofiliano composto por células mais volumosas (Fig. 9).

Devido ao fato do estrato epidérmico mais externo sofrer várias divisões anticlinais para acompanhar o aumento de superfície da folha, essa camada apresenta células menores que as demais. As folhas adultas de P. catharinae (Fig. 8) e $P$. quadrifolia chegam a apresentar as células da epiderme múltipla organizadas em colunas, o que revela sua origem comum com as células mais externas, como foi exposto por Pfitzer (apud Solereder 1908) para P. pereskiaefolia H.B. \& K. e por Linsbauer (apud Esau 1985). Por sua vez, as folhas adultas de P. emarginella e P. rotundifolia apresentam esse mesmo tecido de forma desorganizada (Fig. 9). Pode-se inferir que, neste caso, as células protodérmicas, depois das divisões periclinais, também sofreram divisões oblíquas. $\mathrm{O}$ fato do estrato mais externo da epiderme apresentar paredes mais espessadas que os estratos adjacentes corrobora a idéia de que as células-filhas mais internas da primeira divisão protodérmica periclinal é que dão origem às células de reserva de água. A precoce especialização das células internas da epiderme múltipla justifica suas paredes finas, que por sua vez podem ser consideradas como uma adaptação no caso de perda de água. Assim sendo, as paredes anticlinais das células ficam sinuosas, permitindo diminuição do volume do lume e o não rompimento da parede celular.

A existência da epiderme múltipla já foi descrita para muitas espécies de Peperomia. O tecido de reserva de água das folhas de Peperomia é comumente chamado de hipoderme, inclusive em trabalhos clássicos de anatomia vegetal (Yuncker \& Gray 1934; Metcalfe \& Chalk 1950; 1988; Murty 1960; Datta \& Dasgupta 1977; Gausman et al. 1977). A hipótese desse tecido ser de origem epidérmica já havia sido levantada por Pfitzer (apud Solereder 1908), sendo citada como característica presente em Melastomataceae e Moraceae (Foster 1949), Orchidaceae, Malvaceae e Begoniaceae (Esau 1985; Mauseth 1988).

De acordo com Fahn (1990), a hipoderme é o tecido que se situa internamente à epiderme e é composta por um ou mais estratos específicos de células estruturalmente diferenciadas da epiderme. No sentido mais específico da palavra, refere-se apenas a estratos de tecido que apresentam outra origem que não protodérmica (Linsbauer apud Esau 1985). Por apresentar origem protodérmica, o tecido de reserva de água das folhas de Peperomia pode ser denominado de epiderme múltipla verdadeira (Kaul 1977). Taiz \& Zeiger (1998) e Herrera et al. (2000) chamam essa epiderme de hidrênquima, o que não está de acordo com a nomenclatura usual, pois sendo de origem epidérmica, o tecido não deve levar um nome que referencia um tecido de origem parenquimática. Atualmente, a maioria dos autores denominam esse tecido de epiderme múltipla (Esau 1985; Mauseth 1988; Gibeaut \& Thomson 1989a, 1989b; Christensen-Dean \& Moore 1993; Nishio \& Ting 1993; Raven 1999).

O grau de exposição da epiderme múltipla varia entre as espécies de Peperomia. Algumas delas apresentam os bordos das folhas dobrados, 
de forma que o tecido vítreo preenche o espaço entre eles e mantém pequeno contato com o ambiente (Kaul 1977; Krulik 1980). As folhas das espécies estudadas são dorsiventrais, apresentando o tecido de reserva de água bastante exposto ao ambiente. Mesmo assim, as folhas são carnosas e apresentam grau de suculência elevado, sendo esta variável dependente da espessura da epiderme múltipla. Peperomia rotundifolia apresenta folhas convexas com epiderme múltipla bastante desenvolvida, porém não perde seu aspecto dorsiventral. Paredes pouco espessadas, citoplasma escasso e vacúolo repleto de água são características que corroboram a função de reserva de água das células da epiderme múltipla (Solereder 1908; Gibeaut \& Thomson 1989a).

A epiderme múltipla ocupa mais da metade da espessura das folhas, podendo chegar a mais de $80 \%$, principalmente em ambientes mais iluminados, onde esta é bastante desenvolvida (Takemori 2002). Christensen-Dean \& Moore (1993) concluem em seu trabalho com Peperomia columella que, à medida que a folha se desenvolve, a quantidade relativa da epiderme múltipla aumenta. Sendo assim, os autores concluem que a principal função da folha adulta de uma espécie suculenta é o armazenamento de água. Discorda-se de Christensen-Dean \& Moore (1993) quanto à principal função das folhas adultas, visto que nas espécies analisadas foi observado aumento na espessura desse tecido nas folhas adultas, porém a principal função da folha continua sendo a fotossíntese. A presença da epiderme múltipla é fator que auxilia a fotossíntese, proporcionando água para o tecido fotossintético em períodos de seca. Além disso, a epiderme múltipla age como um filtro de luz, regulando a intensidade luminosa através de sua espessura e sendo esta determinada pela quantidade de luz existente durante o desenvolvimento das folhas (Takemori 2002).

Ontogênese estomática - Os estômatos de Peperomia estão restritos à face abaxial da folha, podendo apresentar de três a cinco células anexas. Pela sua morfologia, podem ser classificados como tetracíticos (Fig. 10-12 e 14), anisocíticos (Fig. 16d, 18d) ou estaurocíticos (Fig. 13 e 14). A ontogênese dos estômatos das quatro espécies analisadas mostrou-se muito semelhante. Nota-se que, de acordo com a forma da célula mãe do estômato (triangular ou retangular), define-se o tipo morfológico.

Os estômatos do tipo tetracítico originamse de uma célula de formato retangular. Esta sofre uma primeira divisão anticlinal, dando origem a duas células, sendo uma maior que a outra. Uma delas é a célula mãe do estômato e a outra, uma célula anexa (Fig. 15a e 17a). A célula mãe do estômato divide-se anticlinalmente formando as células estomáticas e o poro (Fig. 15b e 17b). As demais células anexas surgem a partir de divisões das células protodérmicas adjacentes à célula mãe do estômato (Fig. 15c, 15d, 17c, 17d).

Os estômatos com quatro células anexas foram denominados tetracíticos por apresentar tipicamente duas células polares e duas laterais (Metcalfe \& Chalk 1988). Todavia, nas espécies estudadas alguns estômatos com quatro células adjacentes não apresentam a mesma disposição de um tetracítico típico. Segundo FrynsClassens \& Von Cotten (1973), Baranova (1987) e Metcalfe \& Chalk (1988), estômatos semelhantes a esses são denominados de estaurocíticos (com três a cinco células similares dispostas radialmente às estomáticas e cujas paredes anticlinais cruzam o poro). Considerando que alguns estômatos das espécies analisadas apresentam de três a cinco células anexas (Fig. 13 e 14) dispostas radialmente, preferiu-se denominar os estômatos com essas variações morfológicas de estaurocíticos. Metcalfe \& Chalk (1988) denominam o tipo estomático característico para Piperaceae de ciclocítico. No entanto, nas espécies aqui analisadas não foram registrados estômatos tipicamente ciclocíticos.

O estômato do tipo anisocítico origina-se de uma célula protodérmica que sofre divisão 

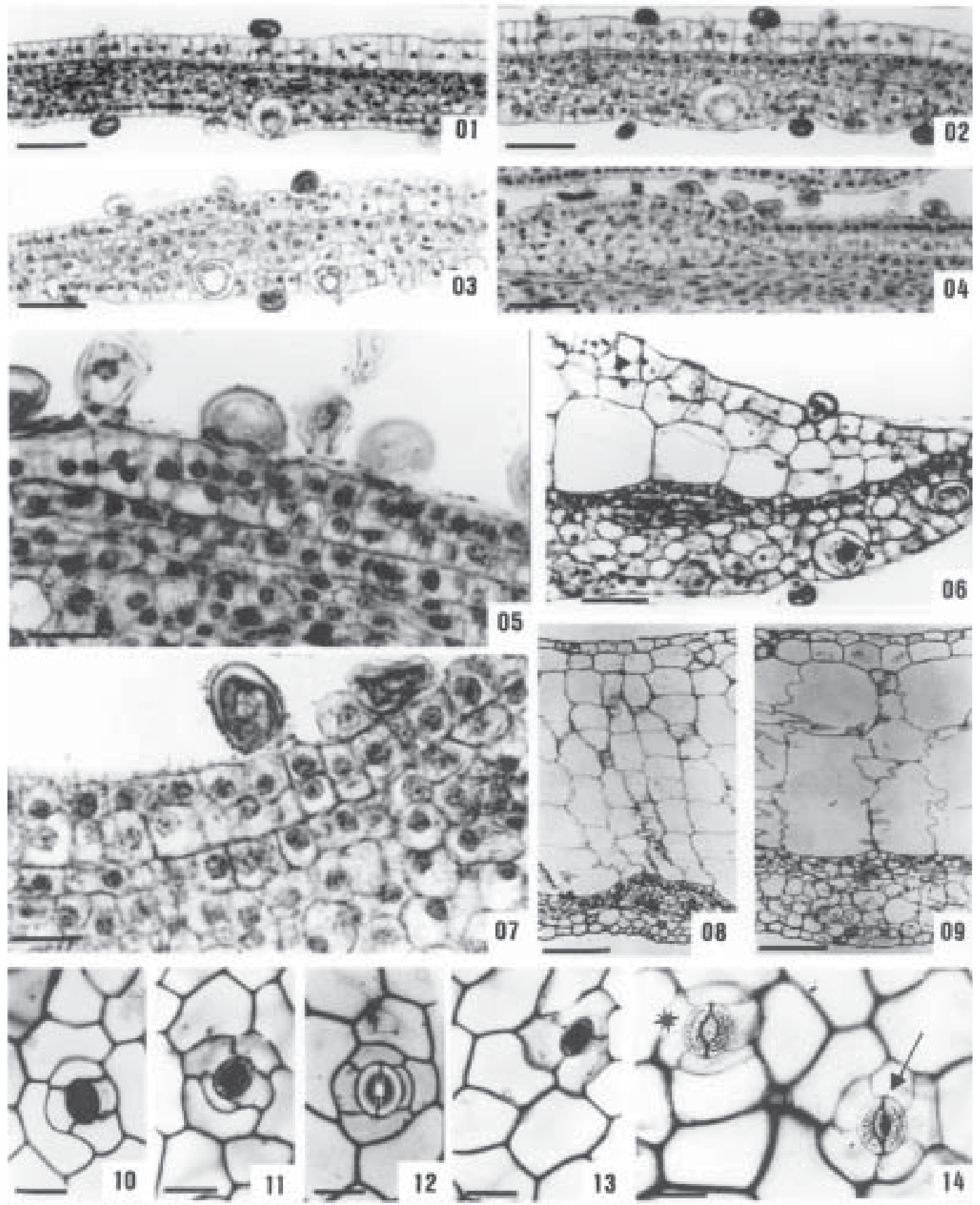

Figuras 1-5. Secções longitudinais da folha jovem. 1. Peperomia catharinae $($ barra $=50 \mu \mathrm{m})$. 2. P. quadrifolia $($ barra $=$ $50 \mu \mathrm{m})$. 3. P. emarginella $($ barra $=50 \mu \mathrm{m})$. 4. P. rotundifolia $($ barra $=50 \mu \mathrm{m})$. 5. P. rotundifolia $($ barra $=20 \mu \mathrm{m})$. Figura 6. Secção transversal da folha jovem de $P$. rotundifolia $($ barra $=50 \mu \mathrm{m})$. Figura 7. Secção longitudinal da folha jovem de $P$. emarginella $($ barra $=20 \mu \mathrm{m})$. Figuras 8-9. Secções transversais da folha adulta $($ barra $=200 \mu \mathrm{m})$. 8. P. catharinae. 9. P. emarginella. Figuras 10-14. Vista frontal epiderme da face abaxial da folha adulta (barra $=35 \mu \mathrm{m})$. 10. Estômato tetracítico de $P$. catharinae. 11. Estômato tetracítico de P. quadrifolia. 12. Estômato tetracítico de P. emarginella. 13. Estômato estaurocítico de $P$. rotundifolia. 14. Estômatos tetracítico (W) e estaurocítico (seta) de P. catharinae. 

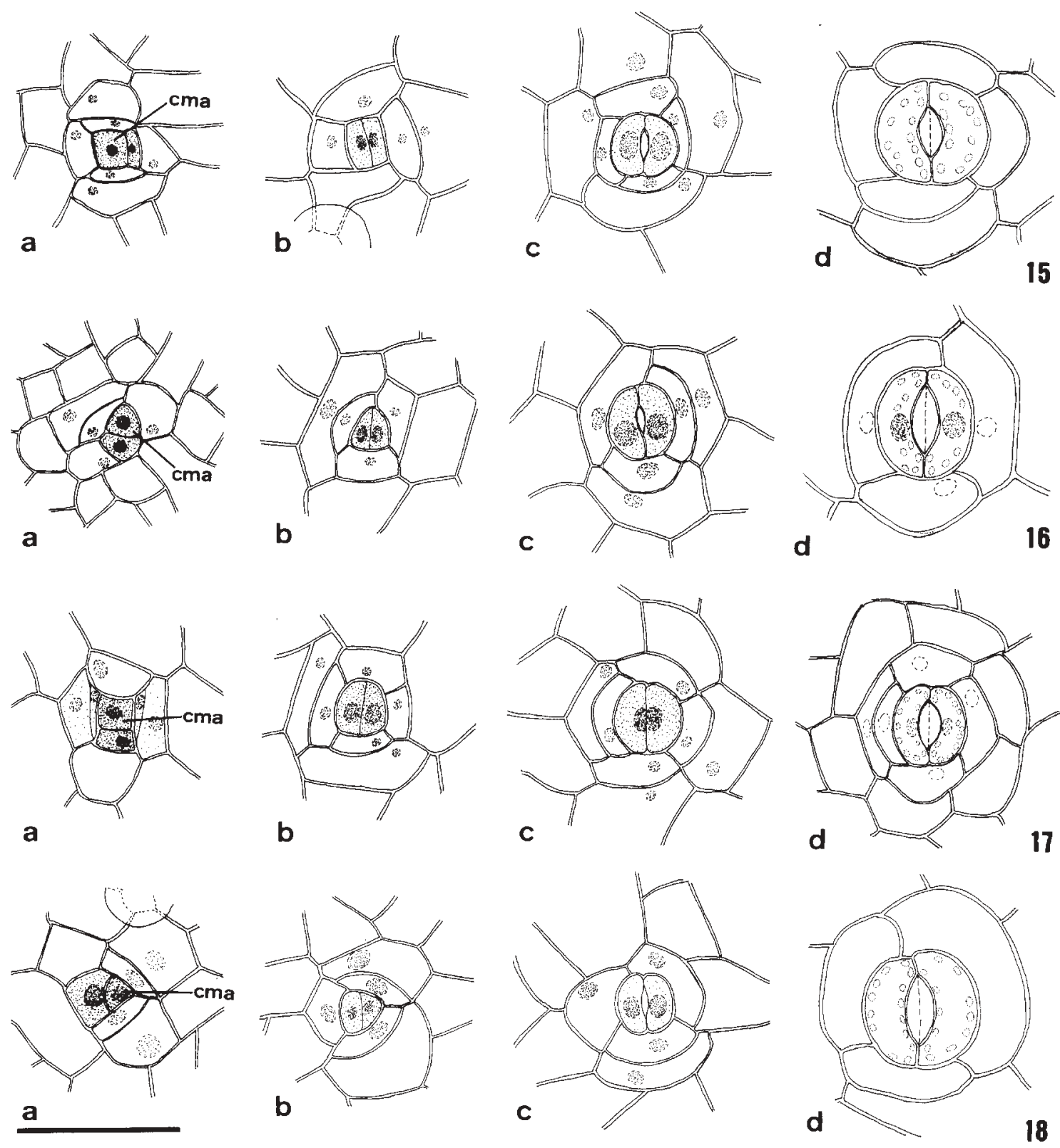

Figuras 15-18. Ontogênese estomática. 15a-d. Peperomia catharinae. 16a-d. P. emarginella. 17a-d. P. quadrifolia. 18a-d. P. rotundifolia. 15a-18a. Origem da célula mãe do estômato (cma). 15b-18b. Divisão anticlinal da célula mãe. $15 \mathrm{c}-18 \mathrm{c}$. Formação do poro. 15d-18d. Estômato adulto. (barra $=42 \mu \mathrm{m})$. 
anticlinal desigual. A célula maior, de formato triangular (trilabrada), é a célula mãe do estômato. A outra, menor, torna-se uma célula anexa (Fig. 16a, 16b, 18a, 18b). A célula mãe do estômato sofre divisão anticlinal que origina as células estomáticas e o poro (Fig. 16b, 18b). Quando as adjacentes se dividem, dão origem às demais células anexas (Fig. 16c, 16d, 18c, $18 \mathrm{~d})$.

De acordo com a classificação proposta por Pant (apud Fryns-Classens \& Von Cotten 1973), a origem dos complexos estomáticos de Peperomia é mesoperígena, pois apresenta células anexas de mesma origem das células estomáticas e de origem diferente. $\mathrm{O}$ fato de haver mais de uma rota ontogênica justifica a existência de mais de um tipo estomático na mesma folha. Em espécies de Peperomia ocorrem estômatos anisocíticos (Pant \& Banerji 1965; Baranova 1987), além de estômatos do tipo tetracítico e anficíclico, com vários anéis de células anexas (Pant \& Banerji 1965). Segundo Pant \& Banerji (1965), a ontogênese dos estômatos anisocíticos de P. pellucida H.B. $\&$ K. e Piper betle L. é do tipo mesógena, sendo todas as células anexas originadas da mesma célula protodérmica que dá origem à célula mãe do estômato, enquanto que a origem mesoperígena é descrita pelo mesmo autor para os estômatos tetracíticos de Piper betle.

A denominação dos tipos morfológicos dos estômatos de Peperomia é realmente difícil e isso fica claro quando se analisa as diversas descrições anatômicas que apenas citam a distribuição dos estômatos nas folhas de Peperomia, sem citar o tipo morfológico (Johnson 1914; Yuncker \& Gray 1934; Murty 1960; Kaul 1977; Sachs \& Novoplanski 1993). Um exemplo é o trabalho de Datta \& Dasgupta (1977) que apenas cita o aspecto das células que circundam as estomáticas. Devido à complexidade morfológica dos estômatos de muitas Piperaceae, percebe-se que muitos autores preferem não se comprometer nomeando-os. Acredita-se que somente uma análise calcada na ontogênese pode, definitivamente, estabelecer os tipos morfológicos dos estômatos de cada espécie.

\section{Agradecimentos}

Os autores agradecem à bióloga Marília Borgo, pelo auxílio na coleta do material botânico; à Profa. Dra. Maria R. Boeger, pelo auxílio na obtenção da bibliografia; aos Laboratórios de Microtécnica e de Botânica Estrutural do Departamento de Botânica da UFPR, pela disponibilização do espaço e dos equipamentos; ao CNPq, pela concessão da bolsa.

\section{Referências bibliográficas}

Baranova, M. A. 1987. Historical development of the present classification of morphological types of stomates. The Botanical Review 53(1): 53-79.

Christensen-Dean \& Moore, R. 1993. Development of chlorenchyma and window tissues in leaves of Peperomia columella. Annals of Botany 71: 141-146.

Datta, P. C. \& Dasgupta, A. 1977. Comparison of vegetative anatomy of Piperales. II - Leaves. Acta Biologica Academiae Scientiarum Hungaricae 28(1): 97-110.

Esau, K. 1985. Anatomía vegetal. Omega, Barcelona.

Fahn, A. 1990. Plant anatomy. 4 ed. Pergamon Press, Oxford.

Feder, N. \& O’Brien, T. P. 1968. Plant microtechnique: some principles and new methods. American Journal of Botany 55(1): 123-142.

Foster, A. S. 1949. Practical anatomy. 1 ed. New York Press, New York.

Fryns-Claessens, E. \& Von Cottem, W. 1973. A new classification of the ontogenetic types of stomata. The Botanical Review 39(1): 71-138.

Gausman, H. W.; Escobar, D. E. \& Knipling, E. B. 1977. Relation of Peperomia obtusifolia's anomalous leaf reflectance to its leaf anatomy. Photogrammetric Engineering and Remote Sensing 43(9): 1183-1185.

Gibeaut, D. M. \& Thomson, W. W. 1989a. Leaf ultrastructure of Peperomia obtusifolia, P. camptotricha and P. scandens. Botanical Gazette 150(2): 108-114. 
Gibeaut, D. M. \& Thomson, W. W. 1989b. Stereology of the internal structures of leaves in Peperomia obtusifolia, P. camptotricha and P. scandens. Botanical Gazette 150(2): 115-121.

Helbsing, S.; Riederer, M. \& Zotz, G. 2000. Cuticles of vascular epiphytes: efficient barriers for water loss after stomatal closure? Annals of Botany 86: 765-769.

Herrera, A.; Fernandez, M. D. \& Taisma, M. A. 2000. Effects of drought on CAM and water relations in plants of Peperomia carnevalii. Annals of Botany 86: $511-517$.

Johansen, D. A. 1940. Plant microtechnique. McGraw-Hill Book, New York.

Johnson, D. S. 1914. Studies of the development of the Piperaceae II. The structure and seed development of Peperomia hispidula. American Journal of Botany 1: 323-339.

Judd, W. S.; Campbell, C. S.; Kellogg, E. A. \& Stevens, P. F. 1999. Plant Systematics: a phylogenetic approach. Sinauer Associates, Sunderland.

Kaul, R. B. 1977. The role of the multiple epidermis in foliar succulence of Peperomia (Piperaceae). Botanical Gazette 138(2): 213-218.

Krulik, G. A. 1980. Light transmission in window-leaved plants. Canadian Journal of Botany 58: 1591-1600.

Lambers, H.; Chapin III, F. S. \& Pons, T. L. 1998. Plant physiological ecology. Springer-Verlag, New York.

Larcher, W. 1995. Physiological plant ecology. Springer-Verlag, Berlin.

Mauseth, J. D. 1988. Plant anatomy. Benjamin Cummings, Menlo Park.

Metcalfe, C. R. \& Chalk, L. 1950. Anatomy of the Dicotyledons. Clarendon, Oxford.

Metcalfe, C. R. \& Chalk, L. 1988. Anatomy of the Dicotyledons. 2 ed. Clarendon, Oxford.

Murty, Y. S. 1960. Studies in the order Piperales - I. A contribution to the study of vegetative anatomy of some species of Peperomia. Phytomorphology 10: 50-59.
Mustard, M. J. 1986. Comparison of stem structure in Florida grown Peperomia. Proceedings of the Florida State Horticultural Society 99: 234-237.

Nishio, J. N. \& Ting, I. P. 1993. Photosynthetic characteristics of the palisade mesophyll and spongy mesophyll in the CAM/C4 intermediate plant, Peperomia camptotricha. Botanica Acta 106: $120-125$.

O’Brien, T. P.; Feder, N. \& McCully, M. E. 1965. Polychromatic staining of plant cell walls by toluidine blue O. Protoplasma 59: 368-373.

Pant, D. D. \& Banerji, R. 1965. Structure and ontogeny of stomata in some Piperaceae. Botanical Journal of the Linneann Society 59: 223-228.

Raven, P. H.; Evert, R. F. \& Eichhorn, S. E. 1999. Biology of plants. 6 ed. W. H. Freeman and Company, New York.

Sachs, T. \& Novoplansky, N. 1993. The development and patterning of stomata and glands in the epidermis of Peperomia. New Phytologist 123: 567-574.

Sipes, D. L. \& Ting, I. P. 1985. Crassulacean acid metabolism and crassulacean acid metabolism modifications in Peperomia camptotricha. Plant Physiology 77: 59-63.

Solereder, H. 1908. Systematic anatomy of the dicotyledons. Clarendon Press, Oxford.

Taiz, L. \& Zeiger, E. 1998. Plant physiology. 2 ed. Sinauer Associates, Sunderland.

Takemori, N. K. 2002. Anatomia comparada de Peperomia catharinae Miquel, P. emarginella (Sw.) C.DC., P quadrifolia (L.) Kunth e $P$. rotundifolia (L.) Kunth (Piperaceae). Dissertação de Mestrado. Universidade Federal do Paraná, Curitiba.

Yuncker, T. G. \& Gray, W. D. 1934. Anatomy of Hawaiian Peperomias. Bernice Pauahi Bishop Museum occasional papers 10(20): 1-19. 